\title{
A protocol for the implementation of new technology in a highly complex hospital environment: the operating room
}

\section{Navin Sewberath Misser*}

Faculty of Management, Science and Technology,

HU University of Applied Sciences and Open University,

Utrecht, The Netherlands

Email: Navin.sewberathmisser@hu.nl

*Corresponding author

\section{Joris Jaspers}

Medical Technology and Innovation (MTKF),

University Medical Center Utrecht,

Utrecht, The Netherlands

Email: J.Jaspers@umcutrecht.nl

\section{Bas van Zaane}

University Medical Center Utrecht,

Utrecht, The Netherlands

Email: B.vanzaane@umcutrecht.nl

\section{Hein Gooszen}

Radboud University Medical Center,

Nijmegen, The Netherlands

Email: Heingooszen67@gmail.com

\section{Johan Versendaal}

Faculty of Management Science and Technology,

Open University and HU University of Applied Sciences,

Utrecht, The Netherlands

Email: Johan.versendaal@ou.nl

\begin{abstract}
Medical equipment is implemented in highly complex hospital environments, such as operating rooms, in hospitals around the world. In operating rooms (ORs), technological equipment is used for surgical activities and activities in support of surgeries. The implementation of government policies in hospitals has resulted in varying implementation activities for (medical) equipment. These result in varying lead times and success rates. An integral and holistic protocol for implementation does not yet exist. In this study, we introduce a protocol for the implementation of (medical) equipment
\end{abstract}


in ORs that consists of implementation factors and implementation activities. Factors and activities are based on data from a systematic literature review and an explorative survey among surgical support staff on factors for the successful implementation of technological and (medical) equipment in ORs. The protocol consists of five factors and related implementation activities: the establishment of a project plan, organisational preparation, technological preparation, maintenance, and training.

Keywords: implementation; protocol; medical technology; (medical) equipment; healthcare; hospital; operating room; operating theatre; integration; scrub nurse; circulating nurse.

Reference to this paper should be made as follows: Sewberath Misser, N., Jaspers, J., van Zaane, B., Gooszen, H. and Versendaal, J. (2020) 'A protocol for the implementation of new technology in a highly complex hospital environment: the operating room', Int. J. Networking and Virtual Organisations, Vol. 22, No. 2, pp.199-217.

Biographical notes: Navin Sewberath Misser holds a Bachelor in Industrial Engineering and Management and a Master in Business Management. As a $\mathrm{PhD}$ researcher he is developing a protocol for implementation of new (medical) equipment in operating rooms at the University Medical Center in Utrecht, The Netherlands. He currently holds a position as head of department Built Environment at the HU University of Applied Sciences in Utrecht, The Netherlands.

Joris Jaspers holds a PhD in Surgical Equipment design and evaluation. As an Associate Professor in Labour Saving Devices at the University Medical Centre (UMC) in Utrecht, the Netherlands, he focuses on the development, clinical feasibility and valorisation of devices that support the medical workforce (labour saving medical devices). Besides his scientific publications, he is inventor on about ten patent applications. He is part time CTO of the start-up company Lapara Surgical BV and member of the supervisory board of the Roessingh Centre for Rehabilitation. He is member of the technological committee of the EAES and the steering committee iSMIT.

Bas van Zaane is an experienced anaesthesiologist and epidemiologist at the University Medical Center Utrecht, The Netherlands.

Hein Gooszen is an experienced pancreatic surgeon and he lastly held a position as Head Department of Pulmonary Diseases a.i. at the Radboud University Medical Center in Nijmegen, The Netherlands. He also was head of the operating rooms department with the OR as academic department as research stream. He led an innovative technological project to develop a medical innovation and technology expert centre at this hospital.

Johan Versendaal holds a position as a Professor E-business at the Open University in Heerlen, The Netherlands. At the HU University of Applied Sciences in Utrecht, The Netherlands he holds the position of professor digital smart services.

This paper is a revised and expanded version of a paper entitled 'Transforming operating rooms: factors for successful implementation of new (medical) equipment', presented at the 31 st eBled Digital Transformation Conference in Bled, Slovenia, 17 June 2018. 


\section{Introduction}

Operating rooms (ORs) or operating theatres are examples of highly complex and dynamic environments where technological equipment is used before, during and after surgeries. Medical equipment is often introduced in ORs and affects the work-related activities of surgeons and surgical support staff. Many case studies have demonstrated the application of technological advancements to improve patient treatments, care and outcomes, but few studies have focused on successful implementations of (medical) equipment in ORs. Edmondson et al. (2001) described the implementation of technological equipment as the integration of new technology in day-to-day activities in an organisation (Edmondson et al., 2001). Implementation of technological equipment entails the integration of equipment that is new to the organisation, which includes new and innovative technology (Tatnall, 2009). The introduction of new and innovative technologies remains a challenge, and governments are becoming increasingly strict. For example, the European Parliament has adopted regulations to increase the safety and safe use of medical devices (Nguyen et al., 2011; European Parliament and Council of the European Union, 2017; European Union, 2017; Regulation of the European Parliament, 2017). These regulations must be implemented before the spring of 2020. In the Netherlands, the Dutch Hospital Association (NZA) has agreed upon a set of rules with regard to the implementation of new medical devices in hospitals: the Covenant Medical Technology (CMT). This agreement provides policy guidelines throughout the lifecycle of (medical) equipment - with regard to its acquisition, implementation, use, and disposal - to ensure patient safety (Dutch Hospital Association, 2016). In the CMT, medical devices are defined as devices that have a direct effect on a patient and the outcome of a treatment. For the purpose of this study, medical devices and (medical) information technology (i.e., hardware and software) are referred to as (medical) equipment. In this study, we also refer to non-medical equipment, which includes equipment that is used in non-surgical or supportive activities. It is possible for supportive activities to not directly affect the patient, their treatment or the outcome of a treatment. The CMT has been implemented in hospitals in the Netherlands, and these hospitals have defined local policies throughout the lifecycle of medical devices. The Health and Youth Care Inspectorate regularly audits these associated local policies. Locally-defined policies have resulted in hospital-specific methods of implementing (medical) equipment and thus in a variety of implementation activities. In turn, this variety has resulted in different implementation outcomes and increased implementation lead times, which can result in the increased use of resources, such as implementation time, funds, and involved members (Wickramasinghe et al., 2008). In our opinion, integral holistic implementation guidelines for (medical) equipment in ORs should be available to ensure safe surgical and treatment interventions. Therefore, we conducted research on necessary factors for the implementation of new (medical) devices in highly complex hospital environments, with a specific focus on ORs, to answer the following research question:

Which factors for successful implementation can be identified to compose a protocol for the implementation of (medical) equipment in ORs? 


\section{Method}

The aforementioned primary research question is operationalised in two sub questions:

1 Which factors for the successful implementation of (medical) equipment in ORs can be identified?

2 Which activities are related to the identified factors for implementation?

We used a mix of research methods to address these sub questions and to explore relevant implementation factors. Relevant implementation factors are necessary to categorise, compose, and populate a protocol for implementation. We performed a systematic literature review to identify success factors for implementation (Sewberath Misser et al., 2018b). As a secondary research method, we prepared a survey. This survey was distributed among the participants of an annual conference for surgical support staff in the Netherlands (scrub nurses and circulating nurses). The following variables were included in this research: necessary steps for implementation, training and governance, user readiness, and other topics such as use of an implementation protocol and the use of the CMT (Sewberath Misser et al., 2018a). Based on these variables, we undertook the following steps to compose protocols for the implementation of (medical) equipment in the OR:

1 Composition of a protocol based on a systematic literature review (protocol A).

In our previous study, we identified seven categories for implementation (Sewberath Misser et al., 2018b). Venkatraman et al. (1993) described a strategic alignment framework, which we used to compare these categories. In this study, we used the dataset of papers that were included in the systematic literature review. We analysed articles in detail to identify factors and implementation activities based on coding results. We used NVivo (version 11 for Windows) to select and analyse related texts' coding results. Identified implementation activities were based on the analysis of the contents of these coded sections in articles. We reviewed and discussed the resulting implementation activities and grouped similar activities. . Included implementation activities were based on frequency and relevance, and were classified under one of the implementation factors. We provided an explanatory description based on the coded categories in NVivo version 11 for Windows.

2 Composition of a protocol based on the findings of a survey that was conducted among surgical supporting staff (protocol B). In this study, we processed the results of the survey in SPSS for Windows and Microsoft Excel (Sewberath Misser et al., 2018a). This explorative survey was distributed among 235 visitors of an annual congress for surgical support staff (scrub and circulating nurses). There were 90 respondents $(n=90)$. We analysed the results of this dataset in detail. We identified implementation activities based on the frequency of relevant activities and provided a description of the input that was used to produce this questionnaire and of the outcomes of the completed surveys. These implementation activities were included in protocol B. 
3 Composition of a combined protocol for the implementation of (medical) equipment. To compose this protocol, we used factors from protocols A and B. We merged these factors in a longlist of categorised factors. This list was then analysed and checked for activities that were similar. The purpose of this analysis was to identify unique and relevant implementation activities, based on protocols A and B. We then discussed and analysed the implementation activities based on their content, the frequency of coding, distinguishing factors, descriptions, activities and/or examples. This analysis resulted in implementation instructions, which were included in this combined protocol.

\section{Results}

The systematic literature review resulted in seven implementation categories (Sewberath Misser et al., 2018b). In Table 1, we provide a mapping of categories that were identified in our previous study compared to the factors that were identified in this study.

Table 1 Mapping of categories compared to implementation factors

\begin{tabular}{lcc}
\hline Number & Factor (in Tables 2 and 4) & Category (as identified in systematic literature review) \\
\hline 1 & Establishment of a project & Project management \\
& plan & Performance \\
2 & Organisational preparation & Process and activities \\
& & Staff \\
3 & Technological preparation & Communication \\
4 & Maintenance & Technology \\
5 & Training & Technology \\
\hline
\end{tabular}

In the next sections, we present the results of our research, based on the sources of data collection. Firstly, we compose a protocol for implementation based on a systematic literature review. This is followed by a protocol for implementation based on survey data among scrub and circulating nurses. Lastly, we combine the data based on the literature and surveys to compose and populate a protocol for the implementation of (medical) equipment in ORs.

\subsection{Protocol A: an implementation protocol based on a systematic literature review}

To compose a protocol for the implementation of (medical) technology, we identified implementation factors and derived implementation activities based on the coded parts of included papers. These implementation factors and activities are presented in Table 2. An explanation of activities is included in the 'description of activities' column and examples of references to literature are provided in the 'reference example' column. 
Based on our systematic review, we distinguished five implementation factors: the establishment of a project plan, organisational preparation, technological preparation, maintenance, and training. Table 2 demonstrates that firstly, a project plan should be established prior to implementation, in which reasons for the implementation of new (medical) equipment should be determined, and involved and affected stakeholders should be identified. Based on the type of equipment, implementation activities should be selected by the project team.

The second factor for implementation involves activities to prepare the organisation for the introduction of equipment. It includes assembling an implementation team, identifying pioneers and ambassadors within the organisation, and assessing affected departments and activities due to the introduction of new (medical) equipment; these departments and employees should be involved in the preparation of the implementation. Protocols must be updated, checklists must be assessed for updates, simulations must be performed to examine how new equipment will be used, and which day-to-day activities need to be adjusted.

The third factor regards the technological preparation. Interfaces with other systems and equipment need to be considered and should function properly.

A fourth factor for implementation is post-implementation maintenance. A maintenance programme should be in place to ensure the safety of equipment after implementation.

The fifth factor is training. Training activities are extensively described in the literature, primarily with regard to technical training for surgeons. Training activities are classified as training in technical and non-technical skills, and these activities should be included in a tailored training programme for various involved stakeholders. For instance, in the case of surgical (medical) equipment, surgeons need to be extensively trained in technical and non-technical skills, while surgical support staff must be trained in the setup and disassembly of this equipment.

\subsection{Protocol B: Survey-based factors and activities}

The second protocol that we present is an implementation protocol based on survey data that was collected from scrub and circulating nurses. We used the same implementation factors as in protocol $\mathrm{A}$, and the implementation activities were based on collected data. These results are presented in Table 3.

As mentioned in the description of activities for first factor in Table 3, "the establishment of a project plan', respondents are advised to inform and involve stakeholders. For the second factor, 'organisational preparation', respondents indicated that protocols must be modified to accommodate the introduction of new equipment, and that simulations are needed to support this. For the 'modify protocols' activity, respondents indicated that day-to-day activities must be adjusted when implementing equipment. They identified introductions and demonstrations of new equipment as necessary activities for the introduction of equipment. These activities were classified as activities for technological preparation. Respondents indicated a number of relevant training activities prior to the introduction of new equipment. These activities mainly concern technical skills and assessment. 
Table 2 Protocol A implementation factors and activities based on literature review

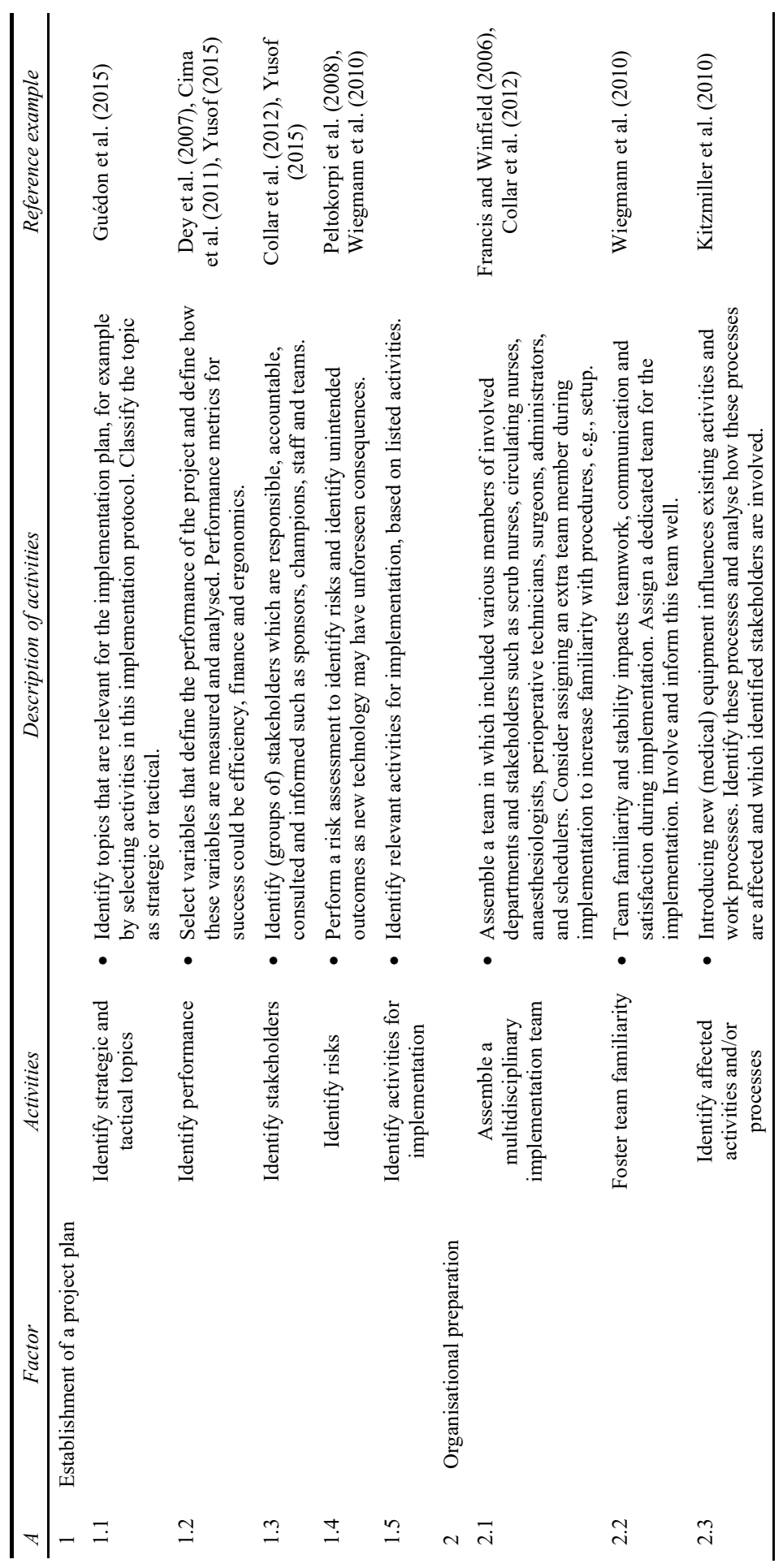


Table 2 Protocol A implementation factors and activities based on literature review (continued)

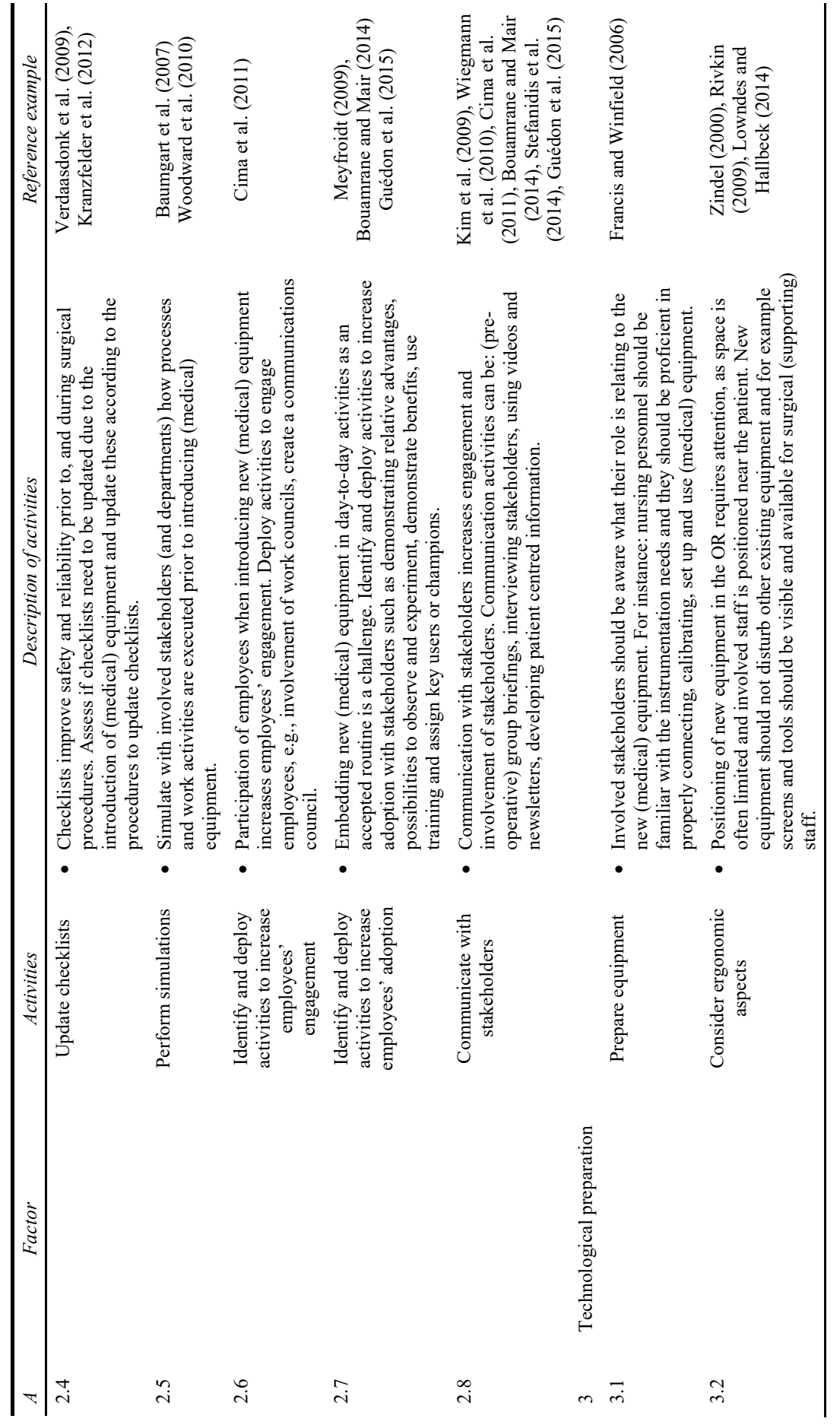


Table 2 Protocol A implementation factors and activities based on literature review (continued)

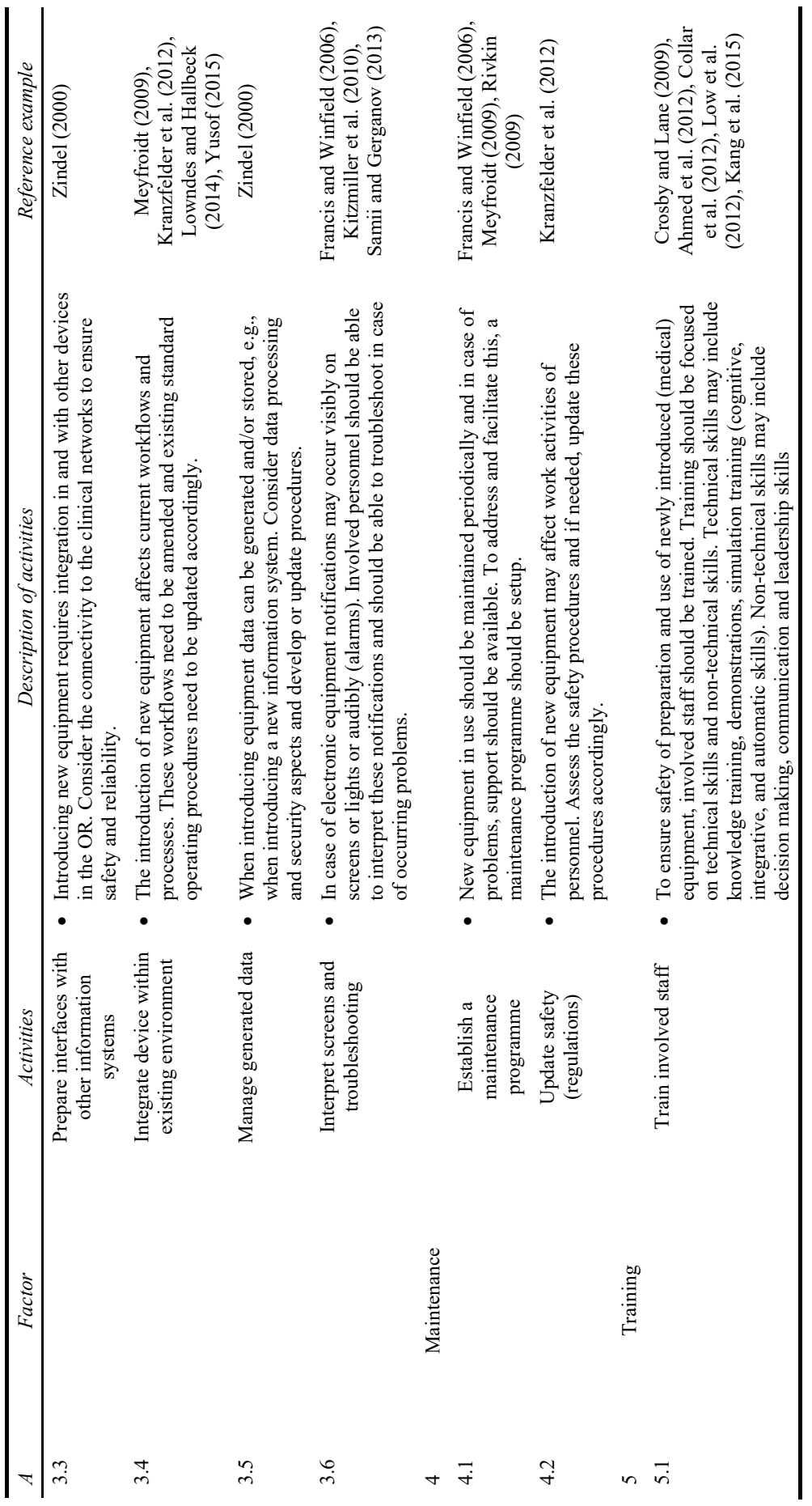


Table 3 Protocol B survey-based factors and activities

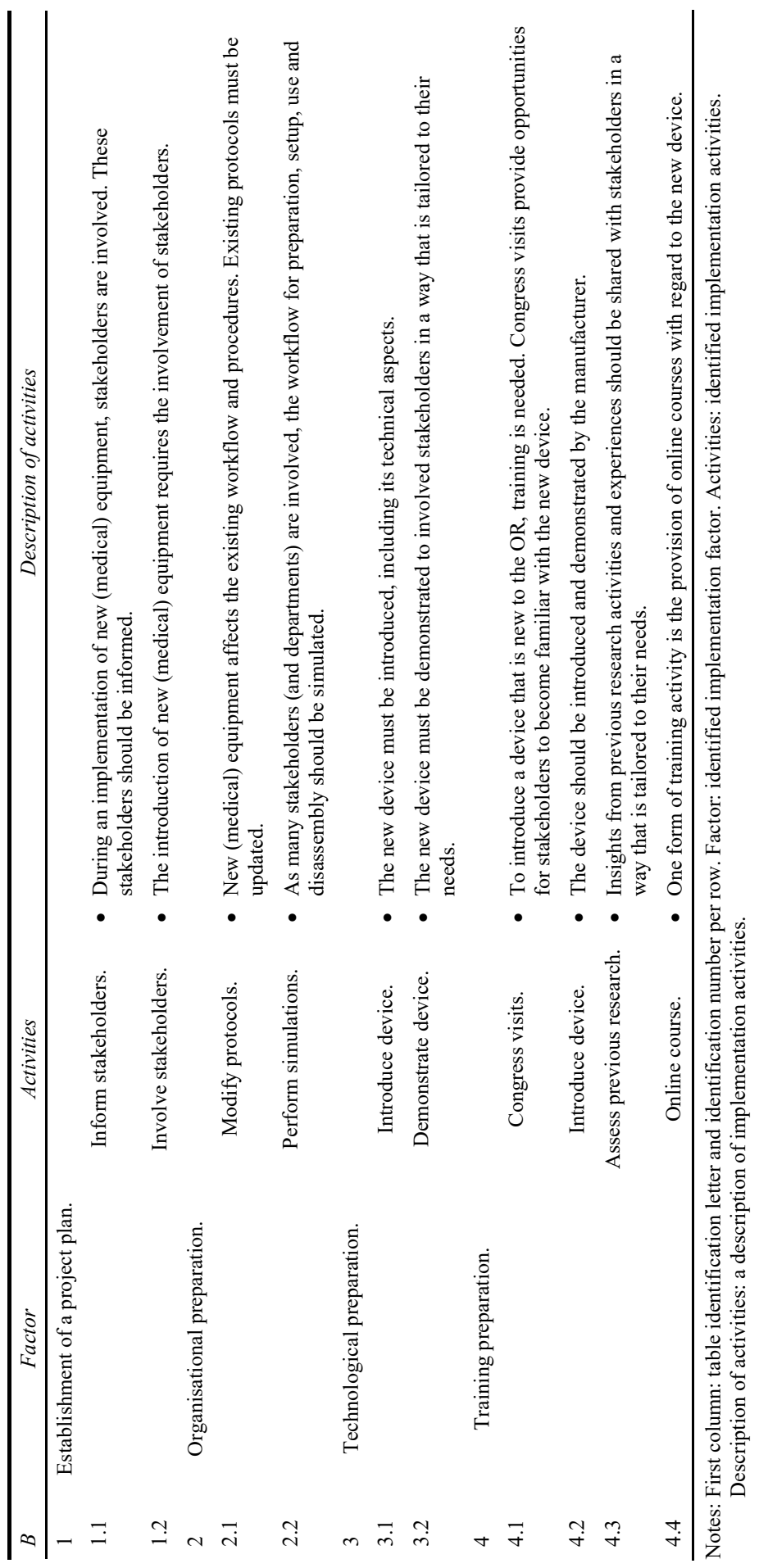


Table 3 Protocol B survey-based factors and activities (continued)

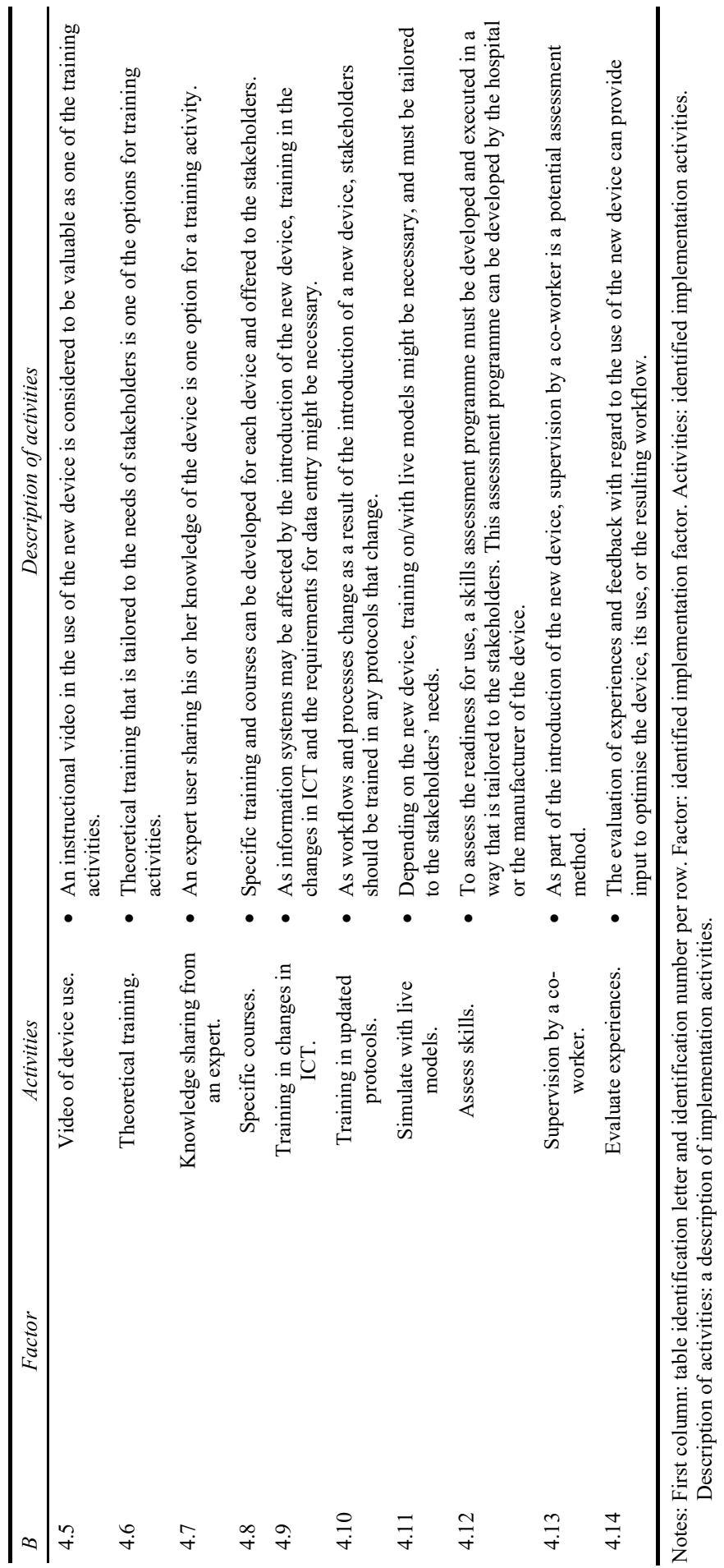


Table 4 Combined implementation protocol for (medical) equipment in the OR

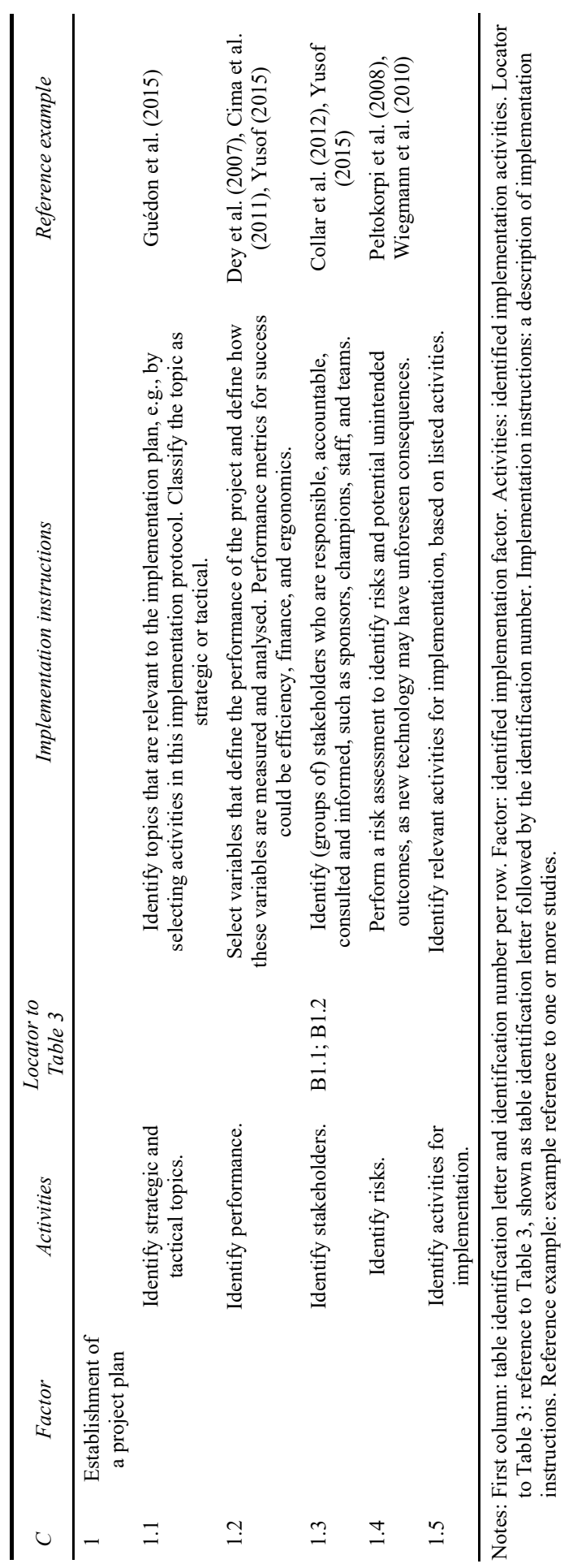


Table 4 Combined implementation protocol for (medical) equipment in the OR (continued)

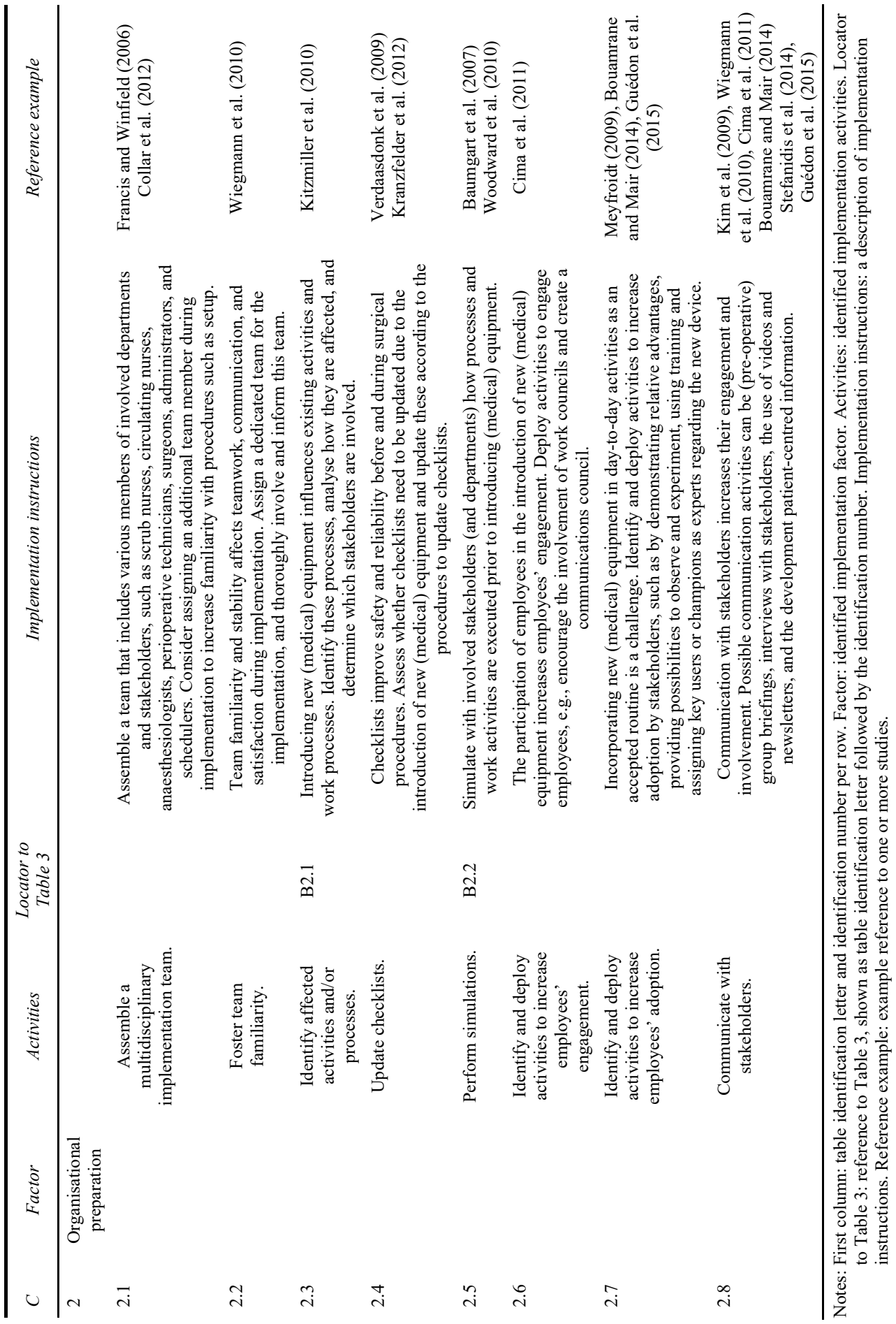


Table 4 Combined implementation protocol for (medical) equipment in the OR (continued)

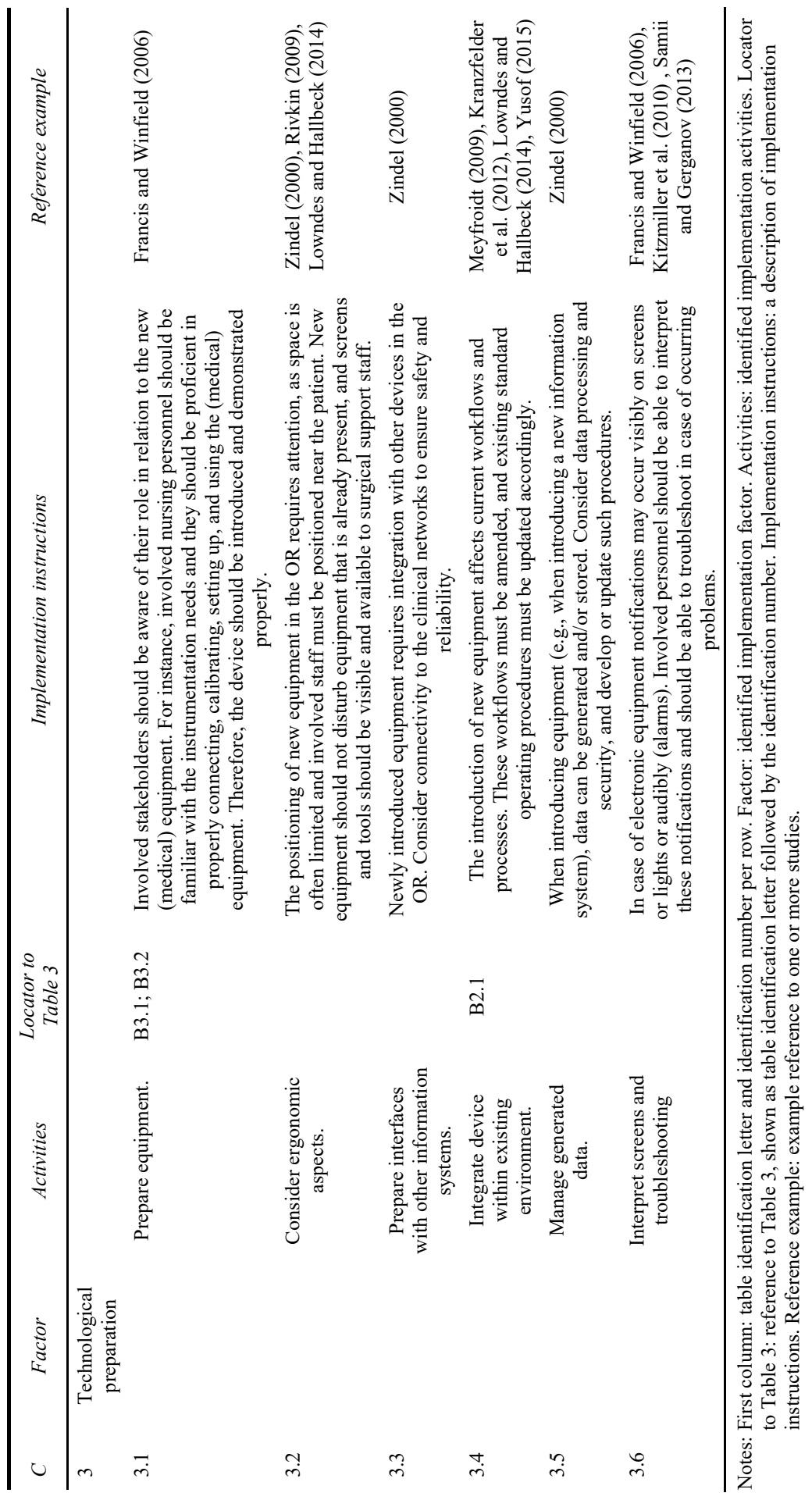




\subsection{Protocol C: combined protocol for implementation}

In this section, we compose a protocol for the implementation of (medical) equipment in ORs. This protocol is based on the merging of data from protocols $\mathrm{A}$ and $\mathrm{B}$, and results are presented in Table 4. As with protocol A, we included factors for implementation and implementation activities. To specify the origin of included activities, we added a locator column to Table 4 that refers to the corresponding section in Table 3 . If included activities were (partly) based on activities in Table 3 (protocol B), we included a reference number, such as Bx.y, which refers to Table 3, protocol B and activity record x.y. For each implementation activity, we added implementation instructions. These instructions are based on data from the surveys and literature.

Like in Table 2 (protocol A), the combined protocol for implementation in Table 4 presents five implementation factors and related activities. The establishment of a project plan is one of the factors for implementation of new (medical) equipment. The purpose of the project, strategic and tactical topics, stakeholders and performance factors should be included in this plan. Activities that are necessary for implementation should be identified and included in a project plan.

The second factor concerns the organisation's preparation for the introduction of the new medical equipment. Employees are involved in this process, and a multidisciplinary team must be assembled to increase the familiarity of the team members with the new equipment. The organisation's preparedness must be analysed, and affected activities and processes need to be identified. Checklists may need to be updated, and simulations of the new device must be prepared. Communication activities need to be identified to involve employees and increase their engagement and adoption.

Besides preparation of the organisation and its employees, activities involving technological preparation are required. Equipment needs to be available and prepared, and the OR must be pre-emptively adjusted to accommodate any potential ergonomic changes. Interfacing with other information systems may require attention prior to integrating new equipment in the OR environment. The use of a new device may generate (new) data, and information systems should be prepared and managed accordingly. Staff should be familiar with the new device and capable of troubleshooting if problems occur. A plan for the maintenance of the new equipment should be developed and implemented.

The final implementation factor in Table 4 involves training. Survey data shows that training is perceived as an important element of the introduction of equipment. These training activities were included in the description of the training of involved staff. Based on the survey data, two implementation activities were included in the combined protocol: the assessment of skills and the evaluation of experiences.

\section{Discussion}

The implementation of technological equipment in highly complex environments, such as ORs, requires careful preparation, coordination, involvement of stakeholders, and training (Tatnall, 2009; Wu and Yezhou, 2011). The implementation of information systems in and outside healthcare has been the topic of research, and success factors for the implementation of these systems have been identified (Bali and Wickramasinghe, 2010). However, research on the implementation of (medical) equipment is limited and lacks an integral protocol. In our experience, research on technological advancements and 
pilot studies on ORs are often conducted, but following up after a pilot study remains difficult. In our view, the implementation of equipment in ORs includes the integration of this equipment in day-to-day activities and its adoption by involved staff and an implementation is more comprehensive and complex compared to a pilot study.

In this study, we have introduced a holistic protocol for the implementation of (medical) equipment in ORs (protocol C). This protocol is based on a systematic literature review and an explorative survey that was conducted among surgical support staff. We explored the factors for successful implementation that were identified in these studies. We reviewed various (case) studies on the use and introduction of (surgical) equipment, information systems and quality assessment methods. The literature review resulted in the identification of five implementation factors: the establishment of a project plan, organisational preparation, technical preparation, maintenance, and training. In this protocol (Table 4) these implementation factors are included, and implementation activities that are based on data from an explorative systematic literature review and a survey (Table 2 and Table 3) are provided. A comparison of survey data with the systematic literature review reveals that many of the activities that were identified by respondents involve training, the adjustment of protocols and processes, and stakeholder involvement, whereas the systematic review provides a broader range of activities, including those with regard to maintenance.

We postulate that the combined implementation protocol, as described in Table 4, has theoretical and practical relevance (Venkatraman et al., 1993). This protocol for implementation contributes to the theoretical knowledge base, and in practice, we consider this protocol to be a baseline for the implementation of (medical) equipment in the OR. We expect that broad use of this protocol will reduce the variety of hospital-specific implementation activities, resulting in more standardised implementation activities. As European regulations on the use of medical equipment increase, we expect that standardised implementation activities will contribute to the safe use of medical equipment in ORs (European Parliament and Council of the European Union, 2017; European Union, 2017; Regulation of the European Parliament, 2017). Furthermore, we expect that this protocol provides flexibility for the implementation of (medical) equipment and non-medical equipment in highly complex environments, such as ORs. Survey results demonstrate that the integration of new equipment in day-to-day activities is a challenge. We expect that the use of this protocol will result in integrated activities, more predictable implementation lead times, and improved outcomes, efficiency and adoption (Edmondson et al., 2001).

\section{$5 \quad$ Limitations}

This protocol is based on various (case) studies of (medical) equipment and an explorative survey that was conducted among surgical support staff. Other members of surgical support staff, such as anaesthetic (support) staff, operators of (medical) equipment and other departments were not included in this study. Their input could potentially increase the number of implementation instructions. This protocol omits a distinction between activities for specific medical equipment, as defined in the CMT, and equipment for supporting activities. This distinction could be identified in future studies, as this protocol requires validation based on empirical data. 


\section{Conclusions and further research}

New medical equipment is implemented in ORs in hospitals around the world, yet an integral protocol for the implementation of such equipment does not currently exist. Based on a systematic literature review and an explorative survey that was conducted among surgical support staff, we have composed a protocol for implementation that consists of five factors and related activities. These factors are the establishment of a project plan, organisational preparation, technological preparation, maintenance, and training. In future studies, we will validate this protocol and related activities, using a pilot study of equipment to be introduced in the OR as an explorative case study. With a focus group, we will assess the completeness and specificity of this protocol. Furthermore, we plan to validate this protocol by implementing equipment in a hospital according to the included implementation factors, activities and instructions.

\section{References}

Ahmed, M., Sevdalis, N., Paige, J., Paragi-Gururaja, R., Nestel, D. and Arora, S. (2012) 'Identifying best practice guidelines for debriefing in surgery: a tri-continental study', The American Journal of Surgery, Vol. 203, No. 4, pp.523-529, DOI: http://dx.doi.org/10.1016/ j.amjsurg.2011.09.024.

Bali, R.K. and Wickramasinghe, N. (2010) 'The critical success factors in the management of projects using innovative approaches', International Journal of Networking and Virtual Organisations, Vol. 7, No. 6, p.497, DOI: 10.1504/ijnvo.2010.035401.

Baumgart, A., Denz, C., Bender, H.J. and Schleppers, A. (2007) 'Computer simulation in operating room management: impacts on process design and performance', 40th Annual Hawaii International Conference on System Sciences (HICSS'07).

Bouamrane, M-M. and Mair, F.S. (2014) 'A study of clinical and information management processes in the surgical pre-assessment clinic', BMC medical informatics and decision making, Vol. 14, p.22, DOI: 10.1186/1472-6947-14-22.

Cima, R.R., Brown, M.J., Hebl, J.R., Moore, R., Rogers, J.C., Kollengode, A., Amstutz, G.J., Weisbrod, C.A., Narr, B.J. and Deschamps, C. (2011) 'Use of lean and six sigma methodology to improve operating room efficiency in a high-volume tertiary-care academic medical center', Journal of the American College of Surgeons, Elsevier Inc., Vol. 213, No. 1, pp.83-92, discussion 93-4, DOI: 10.1016/j.jamcollsurg.2011.02.009.

Collar, R.M., Shuman, A.G., Feiner, S., McGonegal, A.K., Heidel, N., Duck, M., McLean, S.A., Billi, J.E., Healy, D.W. and Bradford, C.R. (2012) 'Lean management in academic surgery', Journal of the American College of Surgeons, Vol. 214, No. 6, pp.928-936, DOI: http://dx.doi.org/10.1016/j.jamcollsurg.2012.03.002.

Crosby, E. and Lane, A. (2009) 'Innovations in anesthesia education: the development and implementation of a resident rotation for advanced airway management', Canadian Journal of Anesthesia/Journal Canadien D'anesthésie, Vol. 56, No. 12, pp.939-959, DOI: 10.1007/ s12630-009-9197-4.

Dey, P.K., Hariharan, S. and Ho, W. (2007) 'Managing healthcare technology in quality management framework', International Journal of Technology Management, Vol. 40, Nos. 1-3, pp.45-68, doi:10.1504/ijtm.2007.013526.

Dutch Hospital Association (2016) Convenant Veilige Toepassing van Medische Technologie in de Medisch Specialistische Zorg, Barnyard Creative Powerhouse, Bilthoven.

Edmondson, A.C., Bohmer, R.M. and Pisano, G.P. (2001) 'Disrupted routines: team learning and new technology implementation in hospitals', Administrative Science Quarterly, Vol. 46, No. 4, pp.685-716. 
European Parliament and Council of the European Union (2017) 'Regulation (EU) 2017/745 of the European Parliament and of the Council of 5 April 2017 on medical devices', Official Journal of the European Union, April, 2014, Vol. 60, pp.1-175 [online] https://www.emergogroup.com/sites/default/files/europe-medical-devices-regulation.pdf $\% 0 \mathrm{~A}$, http://data.europa.eu/eli/reg/2017/745/oj (accessed 12 November 2018).

European Union (2017) 'Medical Devices Regulation (MDR)', Official Journal of the European Union, [online] https://eur-lex.europa.eu/legal-content/EN/TXT/PDF/?uri=OJ:L:2017:117: FULL\& from=EN (accessed 12 November 2018).

Francis, P. and Winfield, H.N. (2006) 'Medical robotics: the impact on perioperative nursing practice', Urologic Nursing, Vol. 26, No. 2, pp.99-109.

Guédon, A.C.P., Wauben, L.S.G.L., de Korne, D.F., Overvelde, M., Dankelman, J. and van den Dobbelsteen, J.J. (2015) 'A RFID specific participatory design approach to support design and implementation of real-time location systems in the operating room.', Journal of Medical Systems, Vol. 39, No. 1, p.168, DOI: 10.1007/s10916-014-0168-0.

Kang, E., Massey, D. and Gillespie, B.M. (2015) 'Factors that influence the non-technical skills performance of scrub nurses: a prospective study', Journal of Advanced Nursing, Vol. 71, No. 12, pp.2846-2857, DOI: 10.1111/jan.12743.

Kim, Y.J., Xiao, Y., Hu, P. and Dutton, R. (2009) 'Staff acceptance of video monitoring for coordination: a video system to support perioperative situation awareness', Journal of Clinical Nursing, England, Vol. 18, No. 16, pp.2366-2371, DOI: 10.1111/j.1365-2702.2008.02429.x.

Kitzmiller, R.R., Anderson, R.A. and McDaniel, R.R. (2010) 'Making sense of health information technology implementation: a qualitative study protocol', Implementation Science: IS, BioMed Central Ltd., Vol. 5, No. 1, p.95 [online] http://www.mendeley.com/research/makingsense-health-information-technology-implementation-qualitative-study-protocol-2/ (accessed 8 February 2016).

Kranzfelder, M., Zywitza, D., Jell, T., Schneider, A., Gillen, S., Friess, H. and Feussner, H. (2012) 'Real-time monitoring for detection of retained surgical sponges and team motion in the surgical operation room using radio-frequency-identification (RFID) technology: a preclinical evaluation', Journal of Surgical Research, Vol. 175, No. 2, pp.191-198, DOI: http://dx.doi.org/10.1016/j.jss.2011.03.029.

Low, D., Walker, I., Heitmiller, E.S. and Kurth, D. (2012) 'Implementing checklists in the operating room', Paediatric Anaesthesia, France, Vol. 22, No. 10, pp.1025-1031, DOI: $10.1111 /$ pan.12018.

Lowndes, B.R. and Hallbeck, M.S. (2014) 'Overview of human factors and ergonomics in the OR, with an emphasis on minimally invasive surgeries', Human Factors and Ergonomics in Manufacturing and Service Industries, Wiley Subscription Services, Inc., A Wiley Company, Vol. 24, No. 3, pp.308-317, DOI: 10.1002/hfm.20383.

Meyfroidt, G. (2009) 'How to implement information technology in the operating room and the intensive care unit', Best Practice and Research Clinical Anaesthesiology, Vol. 23, No. 1, pp.1-14, DOI: 10.1016/j.bpa.2008.07.004.

Nguyen, T.D., Guo, H., Naguib, R.N.G. and Wickramasinghe, N. (2011) 'A view of 21st century healthcare industry and software quality improvement practices', International Journal of Networking and Virtual Organisations, Vol. 9, No. 2, p.155, DOI: 10.1504/ ijnvo.2011.042416.

Peltokorpi, A., Alho, A., Kujala, J., Aitamurto, J. and Parvinen, P. (2008) 'Stakeholder approach for evaluating organizational change projects', International Journal of Health Care Quality Assurance, England, Vol. 21, No. 5, pp.418-434, DOI: 10.1108/09526860810890413.

Regulation of the European Parliament (2017) 'Regulation (EU) 2017/746 - of the European Parliament and of the Council on in vitro diagnostic medical devices and repealing Directive 98/79/EC and Commission Decision 2010/227/EU', Official Journal of the European Union February, 2013, L177, pp.176-331, DOI: http://data.europa.eu/eli/reg/2017/746/oj. 
Rivkin, G. (2009) 'Challenges of technology integration and computer-assisted surgery', The Journal of Bone and Joint Surgery (American), US, Vol. 91, p.13, Supplement_1, DOI: 10.2106/JBJS.H.01410.

Samii, A. and Gerganov, V.M. (2013) 'The dedicated endoscopic operating room', World Neurosurgery, Vol. 79, No. 2, pp.S15.e19-S15.e22, DOI: http://dx.doi.org/10.1016/ j.wneu.2012.02.029.

Sewberath Misser, N., Jaspers, J., van Zaane, B., Gooszen, H. and Versendaal, J. (2018a) 'Transforming operating rooms: factors for successful implementations of new medical equipment', Digital Transformation - Meeting the Challenges, pp.279-289, DOI: 10.18690/978-961-286-170-4.18.

Sewberath Misser, N., van Zaane, B., Jaspers, J.E.N., Gooszen, H. and Versendaal, J. (2018b) 'Implementing medical technological equipment in the OR: factors for successful implementations', Journal of Healthcare Engineering, DOI: https://doi.org/10.1155/2018/ 8502187.

Stefanidis, D., Fanelli, R.D., Price, R. and Richardson, W. (2014) 'SAGES guidelines for the introduction of new technology and techniques', Surgical Endoscopy, Vol. 28, No. 8, pp.2257-71, DOI: 10.1007/s00464-014-3587-6.

Tatnall, A. (2009) 'Innovation translation as a research approach to theorising information systems implementation', International Journal of Networking and Virtual Organisations, Vol. 6, No. 1, p.64, DOI: 10.1504/ijnvo.2009.022484.

Venkatraman, N., Henderson, J.C. and Oldach, S. (1993) 'Continuous strategic alignment: Exploiting information technology capabilities for competitive success', European Management Journal, Vol. 11, No. 2, pp.139-149, DOI: 10.1016/0263-2373(93)90037-I.

Verdaasdonk, E.G.G., Stassen, L.P.S., Widhiasmara, P.P. and Dankelman, J. (2009) 'Requirements for the design and implementation of checklists for surgical processes', Surgical Endoscopy, Germany, Vol. 23, No. 4, pp.715-726, DOI: 10.1007/s00464-008-0044-4.

Wickramasinghe, N., Tumu, S. and Schaffer, J. (2008) 'Critical success factors for video conferencing', International Journal of Networking and Virtual Organisations, Vol. 5, No. 2, p.121, DOI: 10.1504/ijnvo.2008.017006.

Wiegmann, D.A., Eggman, A.A., ElBardissi, A.W., Parker, S.H. and Sundt III, T.M. (2010) 'Improving cardiac surgical care: a work systems approach', Applied Ergonomics, Vol. 41, No. 5, pp.701-712, DOI: http://dx.doi.org/10.1016/j.apergo.2009.12.008.

Woodward, H.I., Mytton, O.T., Lemer, C., Yardley, I.E., Ellis, B.M., Rutter, P.D., Greaves, F.E. C., Noble, D.J., Kelley, E. and Wu, A.W. (2010) 'What have we learned about interventions to reduce medical errors?', Annual Review of Public Health, Vol. 31, No. 1, pp.479-497, DOI: 10.1146/annurev.publhealth.012809.103544.

$\mathrm{Wu}, \mathrm{W}$. and Yezhou, Y. (2011) 'Organisational knowledge transformation and its influencing factors in individual, team and organisational level', International Journal of Networking and Virtual Organisations, Vol. 8, Nos. 3/4, p.192, DOI: 10.1504/ijnvo.2011.039994.

Yusof, M.M. (2015) 'A case study evaluation of a Critical care information system adoption using the socio-technical and fit approach', International Journal of Medical Informatics, M.M. Yusof, Centre for Software Technology and Management, Faculty of Information Science and Technology, Universiti Kebangsaan Malaysia, Bangi, Selangor, Malaysia, Vol. 84, No. 7, pp.486-499, doi:10.1016/j.ijmedinf.2015.03.001.

Zindel, C. (2000) 'System solutions for the integration of devices in the OR', Minim Invasive Ther Allied Technol., Vol. 9, Nos. 3-4, pp.199-205, DOI: 10.1080/13645700009169648. 